\title{
Effects of cigarette smoking on lipid peroxidation and antioxidant status in Iraqi men at Baghdad city
}

\author{
Omar F. Abdul-Rasheed, Wasan T. Al-Rubayee \\ Chemistry and Biochemistry Department, College of Medicine, Al-Nahrain University, Baghdad, Iraq \\ *Corresponding author E-mail: omar_rasheed39@yahoo.com
}

\begin{abstract}
Objectives: To explore the effect of cigarette smoking on lipid peroxidation induced oxidative stress and antioxidants in normal subjects living at Baghdad city- Iraq.

Methods: A case-control study was conducted at Chemistry and Biochemistry Department, College of Medicine, AlNahrain University, Baghdad- Iraq in the period from June 2011 to April 2012. The study included 40 smokers who had been smoking for more than one year and 42 non-smokers healthy volunteers. Malondialdehyde, glutathione and superoxide dismutase were measure spectrophotometrically.

Results: The plasma malondialdehyde level was significantly $(\mathrm{p}<0.05)$ increased in smokers compared with nonsmokers $(0.75 \pm 0.17 \mathrm{nmole} / \mathrm{mL}$ and $0.69 \pm 0.12 \mathrm{nmole} / \mathrm{mL})$ respectively, on the other hand the plasma superoxide dismutase and glutathione were decreased non-significantly in smokers $(0.61 \pm 0.21 \mathrm{U} / \mathrm{mL}$ and $0.44 \pm 0.22 \mathrm{mM})$ respectively compared with those for non-smokers $(0.66 \pm 0.41 \mathrm{U} / \mathrm{mL}$ and $0.50 \pm 0.165 \mathrm{mM})$ respectively.
\end{abstract}

Conclusion: Our study suggests that smoking induces lipid peroxidation with balanced antioxidant status.

Keywords: Glutathione, lipid peroxidation, malondialdehyde, Smoking, superoxide dismutase

\section{Introduction}

Smoking is today provenly recognized as lethally toxic to human system as each cigarette tears away 7-11 minutes of human life [1, 2]. Presently about 1 billion males and 250 million females smoke cigarette/ bidi and about 5 million people die every year from tobacco induced toxicity and unless drastically effective measures are taken the figure is expected to double by 2025[1].

Cigarette smoke contains numerous compounds, many of which are oxidants and prooxidants, capable of producing free radicals and enhancing the oxidative stress [3]. Cigarette smoke is a complex mixture of over 7000 chemical compounds $[4,5]$. Each puff of cigarette smoke contains $10^{14-16}$ Reactive oxygen species (ROS) like superoxide $\left(\mathrm{O}_{2} \bullet\right)$, hydrogen peroxide $\left(\mathrm{H}_{2} \mathrm{O}_{2}\right)$, hydroxyl $(\mathrm{OH} \bullet)$ and peroxyl $(\mathrm{ROO} \bullet$ ) radicals [4]. Free radicals are highly reactive molecules generated by biochemical redox reactions that occur as a part of normal cell metabolism. The human body has an inherent synergistic and multilevel defense mechanism, which comprise of two major classes of cellular protection against ROS. Free radical scavenger enzymes namely SOD, CAT and GPx represent the enzymatic part. The non-enzymatic part includes a large number of natural and synthetic antioxidant compounds (GSH and vitamins) that have the ability to inhibit oxidative stress by scavenging the highly destructive free radicals. The deleterious effects of the free radicals are kept under check by a delicate balance between the rate of their production and the rate of their elimination by these defense systems. When there is an excessive addition of free radicals from exogenous sources added to the endogenous production, the available tissue defense system becomes overwhelmed resulting in oxidative damage to the tissues [6].

Superoxide dismutase (SOD) is the first enzyme in antioxidant defense that scavenges superoxide radicals to form hydrogen peroxide and hence diminishes the toxic effects of the radical. Decreased activity of SOD has been reported in many pathological conditions [6].

Glutathione (GSH), a widely distributed cellular reductant is a metabolic regulator and putative indicator of health. Blood glutathione levels are believed to be predictors of morbidity and mortality [6]. GSH plays a key role in protecting cells against electrophiles and free radicals. 
GSH can act directly as a free radical scavenger by neutralizing hydroxyl radicals, or indirectly by repairing initial damage to macromolecules inflicted by hydroxyl radicals. It is essential in the maintenance of protein and non-protein $\mathrm{SH}$ group in reduced form [6]. Smoking induced depletion of GSH level has also been reported [6].

This study was aimed toward the evaluation of the effect of cigarette smoking on lipid peroxidation and antioxidant status in smoker and non-smoker individuals in Iraq at Baghdad city.

\section{Subjects and Methods}

The present study was carried out at the department of Chemistry and Biochemistry, College of Medicine, Al-Nahrain University, Baghdad, Iraq, in the period from June-2011 to April-2012. This study was approved by the Ethical Committee of Al-Nahrain Medical College, Baghdad, Iraq.

A total of 82 male subjects were included, 40 were individuals who had been smoking cigarettes for more than one year, and 42 were age-matched non-smokers who acted as the controls. All subjects were in the age group of 19-51 years, and were healthy with no evidence of any chronic respiratory disease like asthma, tuberculosis, diabetes mellitus, chronic hepatitis or renal diseases.

A questionnaire was offered to the subjects to obtain information regarding their smoking history, marital status, and education, occupation, drinking habits, vitamin/mineral supplement and drug consumption. The eligibility criteria regarding smoking status were as follows: smokers were eligible if they smoked $\geq 1$ cigarette per day. Non-smokers were eligible if they had not smoked cigarettes for the last one year and had not been exposed to tobacco smoke at all. Subjects who had been were excluded. Exclusion criteria for participation in the study also included an intake of alcohol or tobacco in the past one year.

A blood sample was collected from each subject by using lithium heparin as an anticoagulant. The blood samples were immediately centrifuged at $2000 \mathrm{~g}$ for 5 minutes $\left(4^{\circ} \mathrm{C}\right)$ and plasma was separated and processed for the following analyses.

\subsection{Superoxide dismutase (SOD) determination}

Superoxide dismutase enzyme activity was measured using the rate of inhibition of 2-(4-indophenyl)-(4-nitrophenol)-5phenyltetrazolium chloride reduction method (modified method of Sun et al [7]) using SOD- Randox company kit. One unit of SOD activity was defined as the amount of protein that inhibits the rate of 2-(4-indophenyl)-(4-nitrophenol)-5phenyltetrazolium chloride reduction by $50 \%$.

\subsection{Malondialdehyde (MDA) determination}

MDA levels were determined by the method of Draper and Hadley [8] based on the reaction of MDA with thiobarbituric acid (TBA) at $95^{\circ} \mathrm{C}$. In the TBA test reaction, MDA and TBA react to form a pink pigment with an absorption maximum at $532 \mathrm{~nm}$.

\subsection{GSH determination}

The measurement of glutathione is based on the reaction of aliphatic thiol compounds with 5, 5'-dithiobis (2nitrobenzoic acid) (DTNB) at PH 8 [9].

The results are reported as mean \pm SD. The statistical analysis was done with SPSS 10 version software. Independent sample " $t$ " test and Pearson's correlation coefficient ( $r$ ) were calculated wherever applicable and for all measurements the $\mathrm{p}$ value of less than 0.05 was considered statistically significant.

\section{Results}

Age, body mass index (BMI), number of cigarettes smoked per day, smoking period, systolic and diastolic blood pressures in smokers and non-smokers are given in table (1). 
Table 1: Characteristics of participants

\begin{tabular}{|c|c|c|c|}
\hline Parameters & $\begin{array}{l}\text { Smokers } \mathrm{n}=40 \\
\text { mean } \pm \text { SD }\end{array}$ & $\begin{array}{l}\text { Non-smokers } n=42 \\
\text { mean } \pm \text { SD }\end{array}$ & P-value \\
\hline Age (year) & $31.23 \pm 7.92$ & $29.17 \pm 8.77$ & $>0.05$ \\
\hline BMI $\left(\mathrm{kg} / \mathrm{m}^{2}\right)$ & $27.27 \pm 3.96$ & $25.89 \pm 3.85$ & $<0.05$ \\
\hline No. of cig./day & $25.68 \pm 12.76$ & - & \\
\hline Smoking period (year) & $10.44 \pm 6.78$ & - & \\
\hline $\begin{array}{l}\text { Systolic blood } \\
\text { pressure (mm Hg) }\end{array}$ & $141 \pm 5$ & $123 \pm 3$ & $<0.05$ \\
\hline $\begin{array}{l}\text { Diastolic blood } \\
\text { pressure }(\mathrm{mm} \mathrm{Hg})\end{array}$ & $92 \pm 4$ & $81 \pm 2$ & $<0.05$ \\
\hline
\end{tabular}

The BMI and systolic and diastolic blood pressures were significantly different between smokers and non-smokers.

The glutathione, superoxide dismutase and malondialdehyde levels in smokers and non-smokers individuals were listed in table (2).

Table 2: Biochemical parameters

\begin{tabular}{|l|lll|}
\hline Parameters & $\begin{array}{l}\text { Smokers } \mathrm{n}=40 \\
\text { mean } \pm \text { SD }\end{array}$ & $\begin{array}{l}\text { Non-smokers } \mathrm{n}=42 \\
\text { mean } \pm \text { SD }\end{array}$ & P-value \\
\hline GSH $(\mathrm{mM})$ & $0.44 \pm 0.22$ & $0.50 \pm 0.165$ & $>0.05$ \\
SOD $(\mathrm{U} / \mathrm{mL})$ & $0.61 \pm 0.21$ & $0.66 \pm 0.41$ & $>0.05$ \\
MDA $(\mathrm{nmol} / \mathrm{mL})$ & $0.75 \pm 0.17$ & $0.69 \pm 0.12$ & $<0.05$ \\
\hline
\end{tabular}

The relationship between glutathione and superoxide dismutase with malondialdehyde levels in smokers is given in table (3).

Table 3: Pearson's correlation coefficients in smokers

\begin{tabular}{|l|ll|}
\hline Parameters & Pearson's correlation coefficient $(\mathrm{r})$ & P-value \\
\hline GSH vs. MDA & -0.26 & $<0.05$ \\
SOD vs. MDA & -0.34 & $<0.05$ \\
\hline
\end{tabular}

\section{Discussion}

Cigarette smoking is a serious health problem and most avoidable causes of death in the world. The results in this study illustrates that there were no significant differences in BMI between smokers and non-smokers. Also, it shows that systolic and diastolic blood pressures were significantly higher in cigarette smokers than in non-smokers.

In our study results are similar to studies conducted in other countries $[10,11,12]$. Some studies have reported that smokers have poorer dietary habits and consume significantly ascorbic acid than non-smokers [13], which may be the reason for increase risk of oxidative stress. Analysis of thiobarbituric acid reactive substances (TBARS) in plasma is a widely used method for the evaluation of lipid peroxidation [6].

Regarding to the results in this study, the extent of lipid peroxidation was found to be higher in smokers than in nonsmokers, as shown by the significantly higher levels of plasma $\operatorname{MDA}(\mathrm{P}<0.05)$ (Table 2$)$, these results are consistent with previous studies $[6,18]$. Also the data confirms that cigarette smoking is associated with decreased GSH and SOD levels non-significantly ( $\mathrm{P}>0.05)$, which suggests that with an increase in oxidative stress, there is a corresponding proportionate decrease in the antioxidant defense system, (Table 2).

Cigarette smoke is known to stimulate the alveolar macrophages (AMs) to release excessive levels of free radicals, which are believed to play a role in the development of chronic bronchitis, emphysema and inflammatory diseases [14]. In conclusion it was found that smokers have higher plasma concentrations of MDA compared with nonsmokers inspite of balanced antioxidant profile. This suggests that the observed increase in plasma MDA was induced by smoking per se. While poor antioxidant status presumably also affects lipid peroxidation as shown in several previous studies, the present study shows that it is only partly responsible for the increased level found in smokers in general. The data on antioxidant status in smokers are still more variable and conflicting. Risal et al [15] did not find any difference in plasma TBARS levels between smokers and never-smokers. In the same way to our observations, several workers have noted raised OS in smokers [16-19]. Jain et al [17] examined the TBARS levels in bidi smokers and noted that the TBARS levels were about two times and four times more in mild smokers and heavy smokers respectively. Notably, Lykkesfeldt et al [18] observed high plasma MDA levels in smokers, inspite of balanced antioxidant status. Yang et al 
[19] noted stimulated secretion of pro-inflammatory cytokines in lungs in smokers and attributed it to smoke induced OS. There is still another group which has noted lower OS in smokers [20, 21]. Pearson's correlation coefficients presented in table 3 gives high significant and negative relationship between glutathione and superoxide dismutase levels with malondialdehyde $(r=-0.26 ; r=-0.34)$ respectively. This finding was in accordance with that reported previously [1]. In conclusion, the data of this study indicate that there is a significant increase in lipid peroxidation level and at the same time non-significant decrease of superoxide dismutase and glutathione levels.

\section{References}

[1] J.C. Jha, B.R. Maharjan, D. Adhikari, P. Vishwanath, Akila, T. Nagamma, S. Azhari and P.P. Singh, Cigarette smoke induced oxidative insult in local population of Pokhara, Kathmandu University Med J 5(2007) 511-517.

[2] Mackay J and Eriksen M. The Tobacco Atlas, World Health Organization, Geneva; 2002.

[3] O.G. Arinola, O.M. Akinosun and J.A. Olaniyi, Passive- and active- cigarette smoking: Effects on the levels of antioxidant vitamins, immunoglobulin classes and acute phase reactants, African J Biotech 10(2011) 6130-6132.

[4] T. Nagamma, K. Anjaneyulu, J. Baxi, P. Dayaram and P.P. Singh, Effects of Cigarette Smoking on Lipid Peroxidation and Antioxidant Status in Cancer Patients from Western Nepal, Asian Pasific J Cancer Prev 12(2011) 313-316.

[5] A. Rodgman and T.A. Perfetti, The chemical components of tobacco and tobacco smoke. Boca Raton, FL: CRC Press, Taylor and Francis group, Boca Raton. 2009.

[6] P. Pasupathi, G. Saravanan and J. Farook, Oxidative Stress Bio Markers and Antioxidant Status in Cigarette Smokers Compared to Nonsmokers, J Pharm.Sci \& Res 1(2009)55-62.

[7] Y. Sun, L.W. Oberly and Y. Li, A simple method for clinical assay of superoxide dismutase, Clin Chem 34(1988) 497-500.

[8] H.H. Draper and M. Hadley, Malondialdehyde determination as index of lipid peroxidation, Methods Enzymol 186(1990) $421-431$.

[9] C.W.I. Owens and R.V. Belcher, A colorimetric micro-method for the determination of glutathione, Biochem J 94 (1965)705-711.

[10] J. Ma, J.S. Hampl and N.M. Betts, Antioxidant intakes and smoking status: data from the continuing survey of food intakes by individuals 1994-1996, Am J Clin Nutr 71 (2000)774-80.

[11] J. Lykkesfeldt, S. Christen, L.M. Wallock, et al., Ascorbate is depleted by smoking and repleted by moderate supplementation: a study in male smokers and nonsmokers with matched dietary antioxidant intakes, Am J Clin Nutr 71(2000)530-6.

[12] M. Dietrich, G. Block, E.P. Norkus, et al., Smoking and exposure to environmental tobacco smoke decrease some plasma antioxidants and increase gamma-tocopherol in vivo after adjustment for dietary antioxidant intakes, Am J Clin Nutr 77(2003)160-6.

[13] J.B. McPhillips, C.B. Eaton, K.M. Gans, et al., Dietary differences in smokers and nonsmokers from two southeastern New England communities, J Am Diet Assoc 94 (1994)287-92.

[14] R.P. Baughman, B.C. Corser, S. Strohofer and D. Hendricks, Spontaneous hydrogen peroxide release from alveolar macrophages of some cigarette smokers, J Lab Clin Med 107(1986) 233-237.

[15] S. Risal, D. Adhikari, V.M. Alurkar and P.P. Singh, Oxidative stress and antioxidant status in cardiovascular diseases in population of western Nepal, Kath Univ Med J 4( 2006)271-74.

[16] G. Block, M. Dietrich, E.P. Norkus, J.D. Morrow, M. Hudes, B. Caan and L. Packer, Factors associated with oxidative stress in human population, Am J of Epidem156 (2002) 274-285.

[17] S. Jain, R. Tarun, B.S. Bomb and P.P. Singh, Tobacco users are at greater risk of free radical injury-II. Plasma ascorbic acid and alpha tocopherol in bidi smokers and tobacco users. In: Singh PP, et al editors. Free Radicals and antioxidants in Health and Disease: Concordance and Discordance. Chaudhary Offset Print, Udaipur, India 2007: 71-82.

[18] J. Lykkesfeldt, M. Viscovich and H.E. Poulsen, Plasma malondialdehyde is induced by smoking: a study with balanced antioxidant profiles, Brit J of Nutr 92(2004) 203-06.

[19] S.R. Yang, A.S. Chida and M. Bauter, Cigarette smoke induces pro-inflammatory cytokine release by activation of NF and post translational modifications of histone deacetylase in macrophages, Am J Physiol Lung Cell Mol Physiol 7(2006)335-42.

[20] T. Aghwani, M. Djalali, A. Keshavari, M.R. Sadeghi, H. Zevaati and M. Negahdav, Plasma levels of antioxidant vitamins and lipid peroxidation in breast cancer patients, Iranian J Publ Health 35(2006)42-47.

[21] D. Adhikari, J. Baxi, T. Nagamma, S. Azhari and P.P. Singh, Vitamin C status in cancer patients and healthy subjects from the local population of Pokhara, Kath Univ Med J 4(2006)302-06. 